\title{
Integration of Factory Planning and ERP/MES Systems: Adaptive Simulation Models
}

\author{
Kai Mertins, Markus Rabe, Pavel Gocev \\ Fraunhofer Instiut Produktionsanalgen Konstruktionstechnik (IPK) \\ Pascalstrasse 8-9, 10587 Berlin, Germany
}

\begin{abstract}
The purpose of this paper is to demonstrate the approach of a scalable, flexible and adaptive simulation model used in factory planning on the basis of existing ERP and MES data. The dynamic simulation model was developed to validate and verify the changes of the production yield during factory planning and restructuring in the shop floor. This includes machinery relocation and ramp-up, new product phase-in, product portfolio changes and new product qualification processes. The objective is to enable an industrial engineer without simulation knowledge and experience to perform the simulations. Moreover, the model facilitates an analysis of the results for different scenarios, using the actual data from the ERP and MES systems.
\end{abstract}

\section{Introduction}

Projects that aim to restructure complex production systems concurrently with ongoing system operation are always constrained by customer demand and agreed delivery dates.

Usually restructuring projects are characterised by continuous delays and changes of already planned project activities, which cause modifications of production strategies on a daily basis. The suggestions and modifications can be proved by modelling and simulation of operative activities of the production system and the restructuring actions. The updates of the operating parameters on a daily base trigger the use of simulation models again to simulate the current situation. The daily update of the parameters can be provided by direct insertion of data from an MES system.

In general the data describing the future factory concepts are not contained in company ERP/MES systems due to the early planning phase, uncertainty, or reduced experience of system engineers. This information is usually dispersed in various MSOffice documents containing contradictions and maintained by different people. Usually an additional interface is needed in order to enable the user (analyst) to

Please use the following format when citing this chapter:

Mertins, K., Rabe, M. and Gocev, P., 2008, in IFIP International Federation for Information Processing, Volume 257, Lean Business Systems and Beyond, Tomasz Koch, ed.; (Boston: Springer), pp. 185-193. 
integrate such data without the engagement of a simulation expert and without changing the existing data in the ERP/MES system.

This paper describes a method for the application of a flexible and adaptive simulation model that has already been proved in practice. The factory planning data and data from ERP-/MES systems are integrated in one simulation model that supports the factory planning in the execution of the following activities:

- implementation of new production organisation or layout changes,

- planning of machine relocation and start-up within the shop floor,

- developing of ramp-up plans for new products or product variants,

- scheduling of machine qualifications considering therewith reduced production capability.

The adaptability of the model was proved on manufacturing systems for complex products produced in small series with considerable work content, like railway wagons and gas turbines. The challenge was to support the phases of factory planning and realisation of restructuring. The necessity of planning in short terms (days or weeks) regarding long process times (days) determined the integration of the actual Work-In-Progress (WIP), because a daily manual update was not justifiable due to complexity and the time needed.

\section{Related Work}

Usually simulation models utilise databases extracted from the company's ERP system. Bolmsjö and Randel [10] developed a database driven factory simulation model that utilises the ERP data in order to test the master plan and to find the bottlenecks. The VIVACE project [11] developed a data-driven simulation for a supply chain where the model does not consider the planning and scheduling of orders. For standardisation purposes the National Institute for Standards and Technology (NIST) developed a shop data model and specified the interfaces with the simulation model [12]. The architecture for a generic data driven simulator [13] utilises a simulation model that deploys data from a neutral shop data file. Sivakumar [14] connects ERP/MES data to optimise scheduling integrating the shop-floor data, and allowing the user to enter manually non-system data. Fraunhofer IPA developed a method for web-based configuration and simulation of production systems [15] concerning only the conceptual phase of new production systems. An interface with the operating shop floor is obviously not available. Weiger and Werner [16] developed a simulation model based on data from the ERP system, including a simple scheduling logic. The differences between the performance of a simulation system and the real production system are smoothed when some parameters exceed a user-defined value. The results from the simulation are used for real production system order scheduling by an independent scheduler. Jensen and Hotz [17] developed a method for data consolidation from distributed systems using XMLbased [18] interfaces. The NIST [19] gives an overview of a mechanism to transfer data between a database and XML files used for simulation model generation.

Concerning the optimisation of an existing production system or scheduling and searching for bottlenecks, many related works suggest the integration of data from 
the ERP system. An analysis of the future production system (for factory planning purposes) under consideration of the current shop floor operations is not supported.

\section{Model Architecture}

The manufacturing system was modelled with the simulation software ARENA ${ }^{\circledR}$ (Rockwell Software) [20], using the data that defines products, production capabilities and production schedules. These data serve as a basis for simulation and preparation of the results in an output database for evaluation purposes (Figure 1).

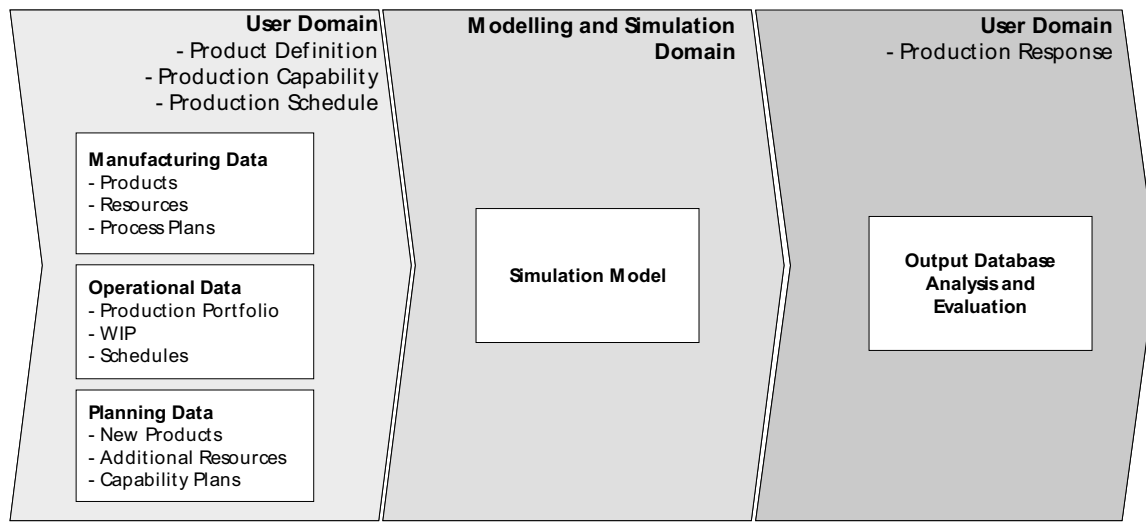

Fig. 1. Simulation Model Architecture

The functions of the model architecture have to enable the user without modelling and simulation proficiency to perform simulations. Due to the nature of the factory planning process the user has to be able to insert new products, new machines and new orders into the model and change the parameters without performing any changes on the simulation model. These requirements can be satisfied only by simulation model architecture with the following features:

- Data consistency - integration of data from ERP/MES systems with continuous changing planning data,

- Flexibility - consideration of new or alternative data or even change (extend or reduce) of already integrated data (from ERP and MES),

- Adaptability - development of simulation scenarios and conduction of a simulation by users without significant simulation experience,

- Customisable - analysis of the results and evaluation of the production system performance defined by the user. 


\subsection{Data Model}

The data required for the simulation and analysis was extracted from the company ERP/MES systems. Utilising structures that are described in the ISA-95 standard [21] the data was transferred in a MS-Access ${ }^{\circledR}$ database for two reasons. Firstly, the planning information and project data for the future production systems and new production portfolios that also have to be considered into the data model are usually dispersed in various MS-Office ${ }^{\circledR}$ documents within the company, or are provided by the partners (e.g. machine vendors). Secondly, the low level of XML knowledge proficiency of ordinary industrial engineers and project (factory planning) managers made it seem critical to use an XML-based interface between ERP/MES and the simulation model.

The data model includes the most necessary data and information for describing production portfolio, equipment list, product model - the Bill-of-Material (BOM) and process plans (basic and alternative).

A very critical issue was the use of simulation model to accompany and monitor the relocation process of the resources. Very long process times and the demand for system performance evaluation on a short-term base have determined the inclusion of the current shop floor status into the simulation instead of using a warm-up period. In order to obtain a basis for a daily simulation performance, the data model includes information and data representing the real shop floor situation (Work In Progress) and the planned (future) situation that was changing almost on a daily basis. According to this fact the data model was extended, enabling to adapt the simulation always to the current situation in the shop floor and avoiding the necessity of a warm-up period. All this yields to more accurate results from the simulation model on a short time basis (weeks, days and even hours). The data that were incorporated into the data model comprise:

- Current resource status.

- Capability plans of the resources related to the shift plan, qualification plan, ramp-up phase, start-up phase and relocation plan.

- Work in Progress (WIP) describing the current status of the materials in the shop floor considering the orders seizing the machines (also number of items already produced within each order) and the status of the waiting orders in the buffer or in front of the machines.

The addition or deletion of some production system elements (products, equipment or orders) or even change of their parameters can be performed without update of the simulation model through entering/deleting of some database records or change of the values. This approach enables the user without modelling and simulation experience to maintain the updates coming from the factory planning process on a daily basis.

\subsection{Simulation Model}

The requirements for a simulation as a support for factory planning that integrates data from ERP/MES systems resulted in the simulation model presented in figure 2 . 


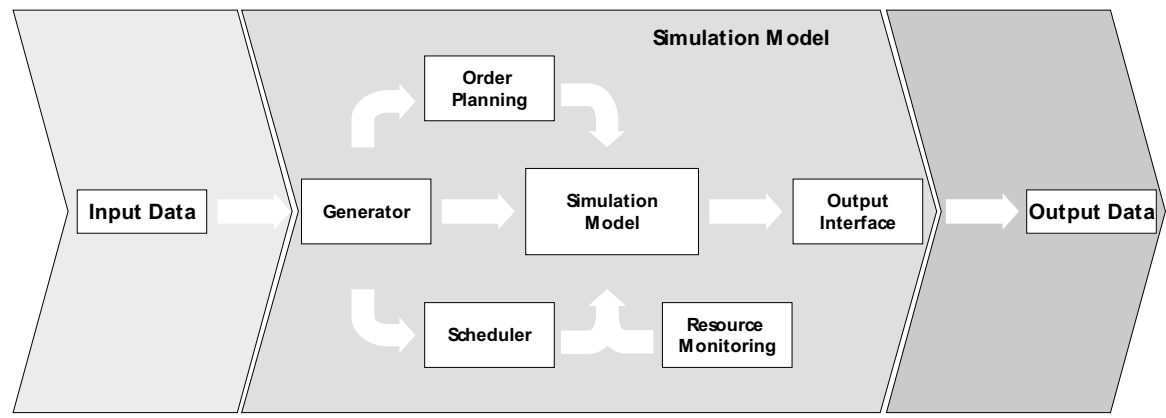

Fig. 2. Simulation Model Components

The generator module is responsible for data integration into the simulation model and initialisation of resources and products with their components. The values of the data are stored as one or two-dimensional array variables.

The production portfolio is processed by the order-planning module that generates production orders for the consisting components of each product from the portfolio. The production orders are further dispatched under consideration of the delivery dates and throughput times deduced from the process plan.

The scheduler module monitors the resources' utilisation and production orders' status and assigns each production order to the basic or the alternative process plan. Alternative resources are assigned in accordance with the waiting times in the queue, due date and machines' status. More accurate results for the production system performance on a short basis were achieved through an interface, which prepares the planned production orders for the MES and receives (from the MES) the scheduled and fine-planned orders as an input for the simulation.

Each production order is presented in the model as an "order entity" and carries information about one product. The process plan related to that product determines the machines where the order will be processed on and the times needed.

The production response information like start/end time, product type, resource and quantity are saved as array variables and stored in the output database.

\subsection{Equipment Capability and Status}

The production capability as an examined characteristic of the production system has a big impact on the simulation model. Very critical for the process of factory planning, estimation of relocation and evaluation plans for the resources and satisfaction of the customer demands was to model, simulate and evaluate all possible statuses of the resources considered with the analysis.

For that reason, in addition to the usual resource statuses like idle, inactive, busy and set-up, other necessary statuses like: rework, failed; in relocation, ramp-up, startup; qualification and maintenance were modelled.

A module for monitoring and assignment of the resource-status within the simulation model controls the resource status and performs:

- changing the status of the resource according to the capability plan, 
- rescheduling the order seizing a machine for which relocation has already started or rescheduling orders waiting in the buffer respectively,

- gathering statistical data for the resources and preparing the values needed for the evaluation.

\subsection{Evaluation and Analysis}

The adaptability of the simulation model architecture extends into the evaluation model. According to the analysis' objectives and user's needs, different granularity levels of evaluation can be selected (product item - batch - order, machine production line - area - site, daily - weekly - monthly - quarterly). The user can change the granularity level in order to provide the most suitable evaluation and support analysts by taking decisions with strategic and operative importance.

The most important recorded data within the output database comprises: customer order number, production order number, product name, production operation ID, machine or production line ID and start-time and end-time for queuing, setting-up and processing on the designated machine. The module for monitoring and assignment of the resource status tracks and controls each resource and records the history data during the simulation. A participative modelling approach (simulation expert and user) leaded to various queries for the evaluation of the database. The queries were developed to enable the analysis of the production system and to present the results as diagrams and report tables needed for strategic decision taking, comprising:

- throughput time of each order or aggregated per product,

- utilisation and status of the resources (weekly, monthly or quarterly),

- adherence to delivery dates (per product, or production order, or customer),

- waiting or queuing times (per product or machine),

- demand on additional capabilities (machines and personnel),

- delays due to the rework,

- inventory levels.

The results are stored as MS Office ${ }^{\circledR}$ files that are suitable for easy comparison of various scenarios or for benchmarking of different products, resources or even production lines.

\section{Model Application}

The model architecture (figure 3) has been used in applications for layout planning of a gas turbine production system and a railway wagon production and assembly system. It is considered to be applicable to other types of small series production with minor customisation and adaptation efforts. However, care has to be taken for modelling the specific business process, and for using suitable reference models. 


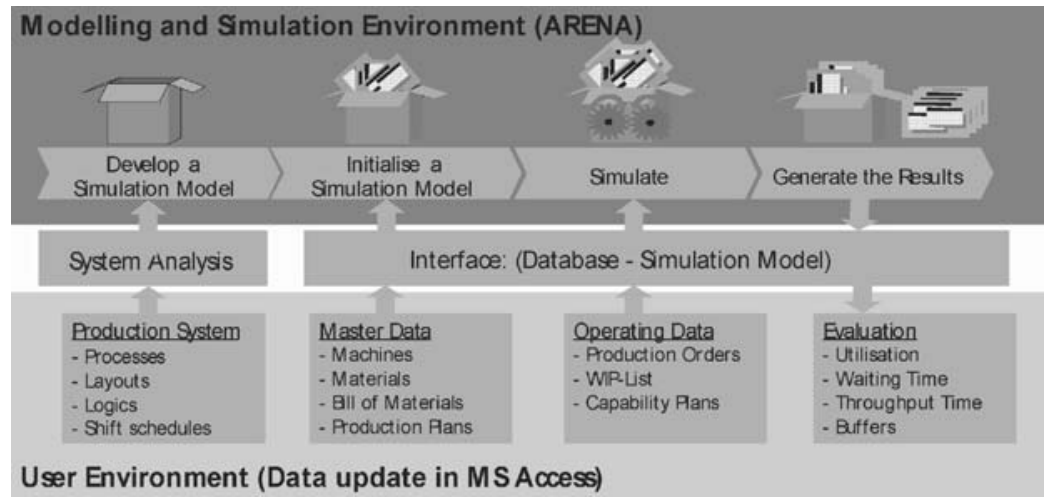

Fig. 3. Simulation Model Architecture

The scope of the model application was to plan the needed capacities during machine relocations within the shop floor under consideration of qualification plans and delivery dates. The emerging tasks to be solved and supported through simulation were development and estimation of: required equipment capabilities, machine-relocation plans, qualification plans and layout concept.

This approach enables the user without further support from modelling and simulation expert to analyse the existing system, to prove new layouts, capabilities, production portfolios and alternative production plans under consideration of actual changes and states on a daily basis.

\section{Conclusions and Further Developments}

A scalable, flexible and adaptable simulation model was developed, integrating ERP/MES and WIP that can be updated and extended by the user. This approach offers an exploration of different scenarios and consideration of the factory planning uncertainties about new products or new equipment. Analysis and evaluation of system performance using the user-defined queries and macros give an additional flexibility.

A supplementary aspect is further development of the interoperability with MES conforming to ISA-95. Furthermore XML interfaces can be developed through the implementation of transactions described by B2MML (Business to Management Mark-up Language) as a part of the ISA-95 standard or BOD (Business Object Documents) specified with the OAGIS ${ }^{\circledR} 9.0$ schema [22]. 


\section{Reference}

1. Mertins, K.; Rabe, M.; Friedland, R.: Simulations-Referenzmodelle erschließen neue Potentiale. In: Zeitschrift für den wirtschaftlichen Fabrikbetrieb (ZWF), 10/96, 91. Jahrgang. Carl Hanser Verlag München, s. 479 - 481.

2. Mertins,K.; Jochem,R.: Quality-Oriented Design of Business Processes. Boston: Kluwer Academic Publishers, 1998.

3. Mertins, K.; Rabe, M.; Jochem, R.: Factory Planning Using Integrated Information and Material Flow Simulation. European Simulation Symposium ESS'94, 09.-12.10.1994, Vol. II, S. 92-96.

4. Mertins, K.; Rabe, M.; Könner, S.: Reference Models for Simulation in the Plannung of Factories. IMACS Symposium on Systems Analysis and Simulation, Berlin 1995, S. 655-658.

5. Mertins, K.; Rabe, M.: Reference Models of Fraunhofer DZ-SIMPROLOG.In: Bernusm P.; Mertins, K.; Schmidt, G. (Hrsg.): Handbook on Architectures of Information Systems. Springer-Verlag, Berlin, Heidelberg, New York 1998, pp. 639649.

6. Mertins, K.: 24.07.1987 Bandung, Indonesien The Role of Simulation in Design of Manufacturing System, Seminar \& Kursus Singkat, Flexible Manufacturing System \& Flexible Manufacturing Cell.

7. Mertins, K.; Rabe, M.; Könner, S.:02.-03.03.1995Magdeburg Integration von Fabriksimulation und CAD. Fachtagung "Integration von Bild, Modell und Text. Otto-von-Guericke-Universität Magdeburg.

8. Mertins, K.:14.02.2002 Tokyo Modelling and Simulation Environments for Design and Planning of Globally Distributed Enterprises - The European Module.MISSION Open Day, Tokyo.

9. Mertins, K.; Rabe, M.; Jäkel, F.-W.3.-5.07.2002Porto, Portugal Distributed Modeling and Simulation of Supply Chains.18th International Conference on CAD/CAM, Robotics and Factories of the Future.

10. Bolmsjö, G., Randell L. (2001) 'Database Driven Factory Simulation: A ProofOf-Concept Demonstrator’, Winter Simulation Conference 2001, pp. 977-983.

11. Cao, B., Farr, R., Byrne, M., Tannock, J. (2005) 'Data-driven Simulation of the Extended Enterprise', 18th International Conference on Production Research.

12. McLean, Lee T., Shao, G., Riddick F. (2005), 'Shop Data Model and Interface Specification', www.mel.nist.gov/msidlibrary/doc/nistir7198.pdf. 
13. McLean, C., Lee T., Riddick F., Jones A. (2002) 'An Architecture for a Generic Data-Driven Machine Shop Simulator', Winter Simulation Conference, 2002, pp.1108-1116.

14. Sivakumar, A.I. (1999) 'Optimization of Cycle Time and Utilization in Semiconductor Test Manufacturing Using Simulation Based, On-Line, Near-RealTime Scheduling System', Winter Simulation Conference 1999, pp. 727-735.

15. Sihn, W., Graupner, T.-D., Kuhlmann, T., Richter, H., (2002) 'Internetbasierte Konfiguration und Simulation von Produktionssystemen', Simulation und Visualisierung 2002. pp.225-235.

16. Weigert G., Werner S., Kellner M. (2002), ,Fertigungsplanung durch prozessbegleitende Simulation', 10. ASIM-Fachtagung, pp. 42-51.

17. Jensen S., Hotz I. (2006), Mit standardisierten Datenstrukturen zur integrativen Simulation', Simulation und Visualisierung 2006, pp. 89-103.

18. www.w3c.org

19. Luo Y., Lee T. Y. (2005) 'Data Exchange for Machine Shop Simulation', Proceedings of the 2005 Winter Simulation Conference, pp. 1446-1452.

20. www.arenasimulation.com

21. www.isa.org

22. www.openapplications.org 